\title{
Rethinking ageing: introduction
}

\author{
Alessandro Blasimme ${ }^{1}$ - Giovanni Boniolo ${ }^{2}$ Marco J. Nathan ${ }^{3}$
}

Accepted: 1 July 2021 / Published online: 6 August 2021

(C) Springer Nature Switzerland AG 2021

While philosophical discussions about the nature of human ageing have never been settled, they acquire new significance in the contemporary milieu. This should be unsurprising, given the rapidly evolving age-structure of our society. According to demographic data, human populations are getting older, especially in the Western hemisphere but, generally, as a world-wide trend (https:/ourworldindata.org/ age-structure). The global percentage of senior citizens is rapidly and consistently increasing. This has raised awareness of the dynamic nature of the ageing process, as well as the diverse ways in which ageing affects people differently, because of biological factors as well as cultural and social determinants.

In recent years, philosophy has started to pay renewed attention to the conceptual and social implications of ageing, especially as they emerged from vivid debates in gerontology and geriatrics. Prominent figures from practical philosophy, in particular from ethics and bioethics, have animated a debate in the so-called philosophy of ageing - often in dialogue with psychiatrist and gerontologists (Scarre, 2016). Philosophers of science have had a considerably more marginal role in this domain of scholarship. This collection thus aims to reflect and, at the same time, expand the

Alessandro Blasimme

alessandro.blasimme@hest.ethz.ch

Giovanni Boniolo

bnlgnn@unife.i

Marco J. Nathan

Nathan@du.edu

1 Department of Health Sciences and Technology, Swiss Federal Institute of Technology - ETH

Zurich, Hottingerstrasse 10, 8092 Zurich, Switzerland

2 Dipartimento Di Neuroscienze E Riabilitazione, Università Di Ferrara, Via Fossato di Mortara 64/A, 44121 Ferrara, Italy

3 Department of Philosophy, University of Denver, 264 Sturm Hall, 2000 E. Asbury Ave, Denver, CO 80208, USA 
paradigm of the philosophy of ageing, giving due relevance to both its socio-ethical and epistemological implications.

\section{Background}

All humans experience the process of getting older, one day after another. Nevertheless, the passing of time per se is not a sufficient condition for ageing. It is only after a certain point in an individual's life that talking about "ageing" proper seems appropriate. For an adolescent, the passing of time does not bear any mark of ageing. Youngsters may be well aware that, as time goes by, there is less for them to live. But in the early phases of a person's life, referring to the passage of time as "ageing" does not sound quite right. The physical, psychological, and medical characteristics that are generally linked to ageing have yet to appear.

While ageing is a familiar concept of ordinary use, it is hard to characterize precisely, and not only from a philosophical point of view. Many other disciplines struggle to provide what may be considered a minimal set of typical features or hallmarks of ageing, let alone a general consensus, even if several attempts have been proposed(for a review, Lemoine, 2020).

Different theories and definitions of ageing have been debated for decades, as witnessed by the success enjoyed, since the late Thirties, by a scholarly genre concerned with the systematic collection of oft-conflicting accounts of ageing from a variety of disciplinary perspectives. In particular, one should mention biogerontology, that studies ageing in relation to structural damage, functional decline, depletion, and other phenotypic changes; social gerontology, dealing with the social impact of ageing; physiology, which analyses changes occurring in all organic systems; psychology, that is interested in natural or pathological cognitive decline (Cowdry, 1939; Burgess, 1960; Tibbitts, 1960; Birren \& Bengtson, 1988; Weinert \& Timiras, 2003; Johnson et al., 2005; Bengtson \& Settersten 2016; Pickard, 2016).

Decades of theoretical studies, alongside a growing body of empirical evidence, have established that the "ageing phenotype" is the result of various concomitant forces - cultural and social, as much as biological. Therefore, biological essentialism, which defines ageing in terms of necessary and sufficient physiological properties, does not seem a viable option. As we all know from direct experience, some people acquire age-related features earlier than others. Others cope better with the effects of ageing and remain youthful until later in life. These differences may depend on a variety of factors, ranging from individual predispositions to environmental conditions, from socio-economic status to the effects of social and even medical attitudes towards given age groups. Paradoxically, however, even as we are discussing the limits of an essentialist view, we can hardly avoid speaking in terms of "life-stages," as if such stages inevitably belonged to human life as natural kinds.

While there is no consensus as to the defining characteristics of ageing, we can observe some relative stability in the way different cultures conceive of human life as the succession of different age-dependent stages spanning youth, adulthood and seniority. Throughout history, there have been many attempts to systematize the periods of life. Interestingly, many of them focus on the number seven, a number 
that early Christian theologians considered significant, as it symbolized completeness. Consider, for instance, the influential Medieval saying: Septem etates homini. The human lifespan was divided into seven stages: "infantia" up to 7 years of age; "pueritia" up to 15; "adolescencia" up to 25; "Juventus" up to 35 ; "virilitas" up to 50 ; "senectus" up 70; "decrepitas," or "gravitas" beyond 70. Setting rhetorical effects aside, the subdivision of the human lifespan into three (another significant number in the history of Christianity), seven or, for that matter, any specific number of stages, does not lend much support to a realistic understanding of ageing. In short, trying to spell out exactly when, over the course of a human life, the passing of time can appropriately be called "ageing" leads us to the heart of philosophically complex matters surrounding the meaning, use, phenomenology, epistemology and ethics of human ageing (Scarre, 2016).

Philosophers have been involved in such disputes for thousands of years. Aristotle's view of ageing as a state of decline caused by a progressive, time-dependent cooling of the body causing a deterioration of character illustrates how evaluative considerations and scientific explanations may often overlap. Aristotle's general approach to ageing remained popular for centuries. Traces can be found in the writings of Galen. Even thinkers like Plato, Cicero and Seneca, who had a more positive attitude towards ageing as bringing about wisdom and a more thoughtful demeanour, linked such features to physical decline as a state that would favour the exercise of those virtues.

As Plato, Cicero, and Seneca remind us, ageing also possesses positive connotations, such as wisdom, knowledge, or experience. Most effects, however, are less desirable, such as undergoing some degree of decline in physical vigour, health, or personal disposition. This is especially true of frequently stigmatized characteristics associated with age-related decline, such as impaired physical autonomy and cognitive function.

\section{The collection}

Any philosophical investigation of the conceptual hallmarks of ageing is further complicated by the observation that all the theoretical accounts of ageing are inevitably interwoven with ethical assumptions about functional fitness, as well as normative judgments concerning the desirability of age-related states. As previously noted, while everyone is familiar with ageing and its consequences, compiling a comprehensive list of the characteristics that distinguish ageing from the mere passage of time is a strikingly complex and controversial endeavour. Trying to examine conceptual and ethical dimensions of ageing in isolation would thus fail to do justice to the philosophical complexity of the topic. With this premise in mind, we have invited both philosophers of science and ethicists to contribute to this topical collection.

From an ontological standpoint, making sense of the concept of ageing raises numerous philosophical challenges. First of all, many discussions of ageing rest on the unchecked intuition that ageing is some sort of natural kind. Such intuition presupposes that breaking down the human lifespan into distinct phases reflects the 
structure of the natural world and tells us something objective about our life trajectory independently of our way of conceptualizing it. But, as observed, this is controversial. To what extent does this assumption withhold serious scrutiny?

Such metaphysical issues, in turn, bear on traditional ethical and social discussions related to age and ageing. For instance, the ways in which evolutionary, biological, and social determinants of ageing stand in relation to one another determine whether or not certain phenotypic manifestations of ageing should be considered as diseases - an important issue with obvious ethical, as well as medical, implications.

The goal of this topical collection is to present and discuss conceptual questions revolving around ageing and to place them in a richer epistemic context. Specifically, the essays collected here represent the efforts of a diverse group of scholars providing a fresh perspective on the meaning of ageing, in light of contemporary scientific and socio-cultural insights. This ecumenical perspective involves putting the philosophy of science and, in particular, a philosophy of the life sciences at the centre of the stage and using it as a springboard to touch upon social and normative issues. On the one hand, philosophers of science must be acutely aware of how values pervade the scientific discourse about ageing. On the other hand, ethicists and bioethicists must factor in the momentous advances in biology and medicine that have taken place over the last few decades. This is the ambitious synergy that we must aspire to, and the essays collected here set a very high bar. Incidentally, this admittedly requires a broad interpretation of philosophy of science. This could not be otherwise, given our focus on an interdisciplinary topic like ageing.

What ties this topical collection together, however, is not merely the need to shed conceptual clarity onto such an intricate matter. Rather, the overarching goal of the essays collected here is to focus on specific aspects of ageing where conceptual analysis can make a difference into the way people conceive of ageing and deal with it in practical terms. Such pragmatic orientation runs through all the essays. For instance, reflecting on the extent to which age-related cognitive decline affects personal identity (see Boniolo in this TC) has implications for the moral agency of people affected by various forms of cognitive impairment. Along similar lines, showing how the process of ageing can be understood as the manifestation of a plastic phenotype (see Blasimme and Sholl in this TC) has crucial implications for public health priorities and strategies to cope with rapidly ageing populations worldwide (see Garson, Nathan, Green \& Hillersdal, and Maung in this TC).

On the other hand, addressing ethical and structural aspects of ageing, the desirability of longevity and the use of digital technologies for elder care (see Gullette, Wareham and Shicktanz in this TC) cannot be separated from background assumptions about what ageing is and whether it can be understood in terms of deficits in relation to an allegedly fully functional phase of human life (see Jecker in this TC).

Another distinctive feature of this topical collection has to do with methodological breadth. Alongside traditional conceptual analysis in the tradition of Audi, 1983 and Iversen, 2009, these essays employ a variety of philosophical techniques and social science tools. Examples include the use of ethnographic data (Green in this TC), historical analysis (Blasimme in this TC), social critique (Gullette in this TC) and normative analysis (Schiktanz and Jecker in this TC). Such methodologies, while rooted in different disciplinary traditions, all cater to the distinctively 
philosophical aim of the collection, that is, to clarify key conceptual quandaries about ageing that have practical implications for the way ageing is understood and dealt with.

Giovanni Boniolo's “Demented Patients and the Quandaries of Identity: Setting the Problem, Advancing a Proposal" focuses on the substantial effects of dementia - decline of memory, attention, learning, language, perception, and social cognition strongly associated with ageing - on the concepts of the self, identity and personhood (Boniolo, 2021). After clarifying the meaning of these key terms, Boniolo advances an empirical thesis concerning personal identity, based on the notion of the whole phenotype account. He defends the claim that patients with dementia are able to maintain their whole phenotype identity. Boniolo concludes by drawing some implications for the capacity of patients with dementia to make moral decisions.

In a paper entitled "Ageing and the Goal of Evolution," Justin Garson proposes to examine a widespread metaphor, according to which the goal or purpose of natural selection is to perpetuate the species (Garson, 2021). Consequently, individuals have the task of breeding and, in some species, raise the brood to maturity. The article begins by illustrating the pervasiveness of this image, showing that this is indeed a metaphor, as opposed to a claim that should be understood literally, and outlining its implications for ageing, namely, the declining force of natural selection with age. At the same time, Garson suggests, this metaphor should be discarded, on the grounds that it distorts our understanding of the evolution of ageing.

Marco J. Nathan's essay "Does Anybody Know What Time It Is? From Biological Age to Biological Time" explores the prospects of developing a truly biological conception of age (Nathan, 2021). Nathan's point of departure is the celebrated 1922 debate between Albert Einstein and Henri Bergson, where Einstein famously proclaimed that the time of the philosopher does not exist. Einstein's dictum has been metabolized across the natural sciences, which typically presuppose, more or less explicitly, the existence of a single, univocal, temporal dimension, ultimately determined by physics. Nathan argues that the standard practice of assessing the ageing of organisms against the backdrop of a physical conception of time is problematic. This becomes especially evident in light of recent discoveries of various levels of senescence underlying the ageing of individual organisms - a phenomenon known as "age mosaicism." The bottom line of these considerations, Nathan concludes, is that the study of ageing requires a truly biological conception of age, as opposed to a physical one.

Hane Maung's article, "What's My Age Again? Age Categories as Interactive Kinds" explores the ontological status of age classification (Maung, 2021). While age categories, such as "young adulthood," "middle adulthood," and "older adulthood" intuitively seem to qualify as natural kinds, this is hard to reconcile with the historical instability of these categories. The properties allegedly captured by age categories are deeply affected by medical and cultural developments. In addition, the very act of classifying people in specific age-related categories can trigger changes in their behaviour which, in turn, affects the properties that we are trying to capture. Maung suggests here that age categories are best understood as interactive kinds that are influenced in dynamic ways by looping effects and explores some implications of this proposal. 
In their article "Ageing Biomarkers and the Measurement of Health and Risk," Sara Green and Line Hillersdal skilfully blend philosophical analysis and ethnographic fieldwork to explore both challenges and opportunities of measuring and managing ageing through bodily signs that are not straightforwardly linked to symptomatic disease (Green \& Hillersdal, 2021). More specifically, this paper documents how the aim to measure and quantify ageing, more precisely, as risk is confronted with both experimental and conceptual challenges. They conclude by highlighting that the reframing of ageing qua risk has social and ethical implications, as it is generative of normative notions of what constitutes successful ageing and good citizenship.

In his article "The Plasticity of Ageing and the rediscovery of ground-state prevention" Alessandro Blasimme explores how the ageing-phenotype grew as a proper object of medical intervention since the birth of modern geriatric medicine in the mid-twentieth century until the emergence of novel biomedical insights, in the last decade (Blasimme, 2021). The article also shows that a new understanding of prevention is associated to seeing ageing as a plastic phenotype - one that bears resemblance with long-held medical ideals about the preservation of health throughout one's life.

Along similar lines, Jonathan Sholl's article, "Can Ageing Research Generate a Theory of Health?" explores the prospects of developing a general theory of health (Sholl, 2021). He begins with some generalizations about "health" implicit within research on robust scientific descriptions of ageing and its modulators. By extracting, explicating, and evaluating one potential construct of health in these models, Sholl proposes a theory of health based on the trajectory of optimized phenotypic trade-offs.

Christopher Wareham, in his paper "Between Hoping to Die and Longing to Live Longer", offers a meticulous ethical analysis on the desirability of longevity (Wareham, 2021). Wareham constructs his analysis of this classical philosophical theme around contemporary debates on the morality of intentionally setting a limit to one's life span. He argues against the idea that aiming to live beyond a certain old age is not worth hoping for, he shows that contemplating death may have an instrumental value in shaping one's purposes and motivating one to act towards them.

In her essay titled "Ageism in State Power and Literary Culture: Preparing the Way for the COVID-Era Eldercide in the United States" age-studies scholar Margaret Morganroth Gullette explores the cultural underpinnings of derogatory conceptions of old age and their practical consequences in the context of the SARSCoV-2 pandemic. Her article illustrates deep-seeded ageist prejudices underpinning discourses about old age - including the philosophical discussions on the limits of longevity covered by Wareham - and shows how they explain the appalling toll of avoidable deaths that occurred among elders, especially in long-term care facilities.

Silke Schiktanz and Mark Schweda, in their paper "Ageing 4.0? - Rethinking the Ethical Framing of Technology-assisted Eldercare" present a normative analysis of novel assistive technologies. In particular, they focus on self-tracking and monitoring technologies, including those relying on digital platforms and employing smart approaches and artificial intelligence. This analysis shows how the use of such technologies has ethical implications regarding the autonomy of the assisted person, her 
capacity for self-determination, her privacy, well-being and her right to equitable and fair access to eldercare.

Nancy Jecker' s “The Time of One's Life: Views of Ageing and Age Group Justice" tackles issues of intergenerational justice in light of different possible accounts of ageing and their normative implications (Jecker, 2021). Jecker illustrates how what she calls a midlife bias - that is, the tendency to apply values central for people during midlife to all life stages - sustains views of ageing that neglect the biographical unity of human life in favour of a snapshot view of the midlife self. Such different images of human life support different understandings of age group justice as either interpersonal or first-person problems. Instead of considering these approaches as mutually exclusive, Jecker suggests that they can inform different but equally important practical and normative purposes.

In conclusion, while the import of ageing as a biological and social phenomenon is widely recognized in the biomedical science, it has received surprisingly little attention in the philosophy of the life sciences and cognate fields. The goal of this edited collection is to begin filling in this gap, by discussing the metaphysical, epistemological, and ethical implications of ageing, broadly construed, as well as the philosophical implications of extant biomedical practices.

These essays are the outcome of a workshop that was held on December 12-13, 2019 at the Civitas Vitae Research Centre of the Fondazione OIC Onlus in Padova, Italy, in partnership with the Health Ethics and Policy Lab of the Swiss Federal Institute of Technology_ETH Zurich.

Acknowledgements The authors are grateful to Sabina Leonelli and Mallory Hrehor for constructive comments on this paper, as well as to the Fondazione OIC (Civitas Vitae Research Centre) and ETH Zurich for supporting this project. $\mathrm{AB}$ would like to acknowledge the European Commission and the Swiss National Science Foundation for their support to the ERA-NET Neuron project BEAD "Optimizing the aging Brain? Situating Ethical Aspects of Dementia Prevention".

\section{References}

Audi, R. (1983). The applications of conceptual analysis. Metaphilosophy, 14(2), 87-106.

Bengtson, V.L., Settersten Jr, R. (eds.) (2016), Handbook of theories of aging. Springer.

Birren, J. E., \& Bengtson, V. L. (1988). Emergent theories of aging. Springer.

Blasimme, A. (2021). The plasticity of ageing and the rediscovery of ground-state prevention. History and Philosophy of the Life Sciences, 43(2), 1-18.

Boniolo, G. (2021). Demented patients and the quandaries of identity: Setting the problem, advancing a proposal. History and Philosophy of the Life Sciences, 43(1), 1-16.

Burgess, E. W. (1960). Aging in Western societies. University of Chicago Press.

Cowdry, E.V. ed. (1939), Problems of ageing: Biological and medical aspects. Baltimore: Williams and Wilkin $(1942,1952)$.

Garson, J. (2021). Ageing and the goal of evolution. History and Philosophy of the Life Sciences, 43(1), $1-16$.

Green, S., \& Hillersdal, L. (2021). Aging biomarkers and the measurement of health and risk. History and Philosophy of the Life Sciences, 43(1), 1-23.

Iversen, T. N., et al. (2009). A conceptual analysis of ageism. Nord Psychol, 61(3), 4-22.

Jecker, N. S. (2021). The time of one's life: Views of aging and age group justice. History and Philosophy of the Life Sciences, 43(1), 1-14.

Johnson, M.L (eds.), (2005). The Cambridge handbook of age and ageing. Cambridge University Press. 
Lemoine, M. (2020), Defining aging. Biol Philos 35, 46; https://doi.org/10.1007/s10539-020-09765-Z

Maung, H. H. (2021). What's my age again? Age categories as interactive kinds. History and Philosophy of the Life Sciences, 43(1), 1-24.

Nathan, M. J. (2021). Does anybody really know what time it is? History and Philosophy of the Life Sciences, 43(1), 1-16.

Pickard, S. (2016). Age studies a sociological examination of how we age and are aged through the life course. London: Sage Publishing.

Scarre, G. (ed.), The Palgrave handbook of the philosophy of ageing, Palgrave MacMillan 2016.

Sholl, J. (2021). Can aging research generate a theory of health? History and Philosophy of the Life Sciences, 43(2), 1-26.

Tibbitts, C. (1960). Handbook of social gerontology: Societal aspects of aging. University of Chicago Press.

Wareham, C. S. (2021). Between hoping to die and longing to live longer. History and Philosophy of the Life Sciences, 43(2), 1-20.

Weinert, B. T., \& Timiras, P. S. (2003). Theories of aging. Journal of Applied Physiology, 95, 1706-1716.

Publisher's Note Springer Nature remains neutral with regard to jurisdictional claims in published maps and institutional affiliations. 